\title{
Monitoring local well-being in environmental interventions: a consideration of practical trade-offs
}

\author{
B. Palmer Fry, M. Agarmala, G. Atininson, T. Clements, K. Homenood \\ S. Mourato, J.M. Rowchiffe, G. Wallace and E. J. Milner-Gulland
}

\begin{abstract}
Within the field of environmental management and conservation, the concept of well-being is starting to gain traction in monitoring the socio-economic and cultural impact of interventions on local people. Here we consider the practical trade-offs policy makers and practitioners must navigate when utilizing the concept of well-being in environmental interventions. We first review current concepts of well-being before considering the need to balance the complexity and practical applicability of the definition used and to consider both positive and negative components of well-being. A key determinant of how well-being is operationalized is the identity of the organization wishing to monitor it. We describe the trade-offs around the external and internal validity of different approaches to measuring well-being and the relative contributions of qualitative and quantitative information to understanding well-being. We explore how these trade-offs may be decided as a result of a power struggle between stakeholders. Well-being is a complex, multi-dimensional, dynamic concept that cannot be easily defined and measured. Local perspectives are often missed during the project design process as a result of the more powerful voices of national governments and international NGOs, so for equity and local relevance it is important to ensure these perspectives are represented at a high level in project design and implementation.
\end{abstract}

Keywords Conservation, evaluation, happiness, monitoring, validity, well-being

B. Palmer Fry and E.J. Milner-Gulland* (Corresponding author) Centre for Environmental Policy and Department of Life Sciences, Silwood Park Campus, Imperial College London, UK

E-mail e.j.milner-gulland@imperial.ac.uk

M. Agarwalat, G. Atkinson and S. Mourato Geography \& Environment Department, London School of Economics, UK

T. Clements Wildlife Conservation Society, Bronx, New York, USA

K. Homewood Anthropology Department, University College London, UK

J.M. RowCLIFFE Institute of Zoology, Zoological Society of London, UK

G. WALLACE Frankfurt Zoological Society, Zambia and Tanzania

${ }^{*}$ Current address: Department of Zoology, University of Oxford, UK

$\dagger$ Also at: School of Environmental Sciences, University of East Anglia, UK, and Centre for Social and Economic Research on the Global Environment (CSERGE), University of Exeter, UK

Received 14 July 2015. Accepted 25 August 2015.

First published online 28 October 2015.

\section{Introduction}

ractitioners and policy makers in the field of environ1 mental management are becoming increasingly aware that genuine involvement of local people is centrally important to long-term project success (Brashares \& Sam, 2005; Skutsch et al., 2009; Danielsen et al., 2011). Without free, prior and informed consent, integrated local involvement, clear benefit sharing and community ownership, environmental projects are likely to lack sustainability (TFD, 2012; Harvey \& Reed, 2007; Waylen et al., 2010). Thus to evaluate the impact of environmental interventions, it is necessary to assess both the human and natural parts: ecological and human dynamics cannot be separated (Liu et al., 2007). By definition 'environmental interventions' are environmentally focused policy or project actions that lead to localized changes in existing systems but that might additionally have human-centred goals, which may range from positive benefit for the surrounding population to 'doing no harm'. Intervention 'success', therefore, is characterized by the achievement of these ecological and human goals. The complex social, economic and environmental landscapes that frame interventions make effective monitoring of change very difficult (Christie, 2004). Monitoring changes in the biophysical environment has received much attention from natural scientists over the years (Millennium Ecosystem Assessment, 2005). These same specialists have also commonly been responsible for monitoring the impacts of interventions on people, an area in which they may not have sufficient experience or training. In response to a deeper understanding of the coupling of social and natural systems, modern conservation science is beginning to draw more readily upon social science expertise and approaches, and thereby is becoming increasingly interdisciplinary and convergent with the field of sustainable development (Roe, 2008; Kareiva \& Marvier, 2012).

Although the poorest people are often those most directly reliant on functioning biophysical systems (e.g. Bahuguna, 2000; Kepe et al., 2004), policies aimed at conserving these systems frequently marginalize this socioeconomic group as a result of factors such as an overemphasis on local rather than global drivers of degradation, and insufficient attention to distributional issues such as elite capture. For example, Lenzen et al. (2012) demonstrate that $30 \%$ of the threats to Red Listed species are caused by international trade, rather than by locally-originating 
factors. Sommerville et al. (2010) asked local people about their perceptions of the fairness of a Payments for Ecosystem Services scheme in Madagascar. They found that village elites benefited substantially from the intervention whereas more marginalized groups, who were most dependent on the forest resources that the scheme aimed to protect, were not receiving benefits commensurate with the costs imposed by conservation.

A more nuanced understanding of the social impacts of environmental projects is necessary if interventions are to be sustainably pro-poor (Blomley \& Franks, 2009). One lens through which socio-economic and cultural impact can be discerned is individual well-being, defined by the Oxford English Dictionary as 'a state characterized by health, happiness and prosperity' (Agarwala et al., 2014). Scholars and practitioners need a rigorous understanding of the wellbeing concept to develop and implement frameworks to monitor the intentional or unintentional impacts that environmental interventions have on local people. Agarwala et al. (2014) provided a review of the different well-being conceptualizations and monitoring frameworks, and MilnerGulland et al. (2014) looked at why well-being is of particular interest to conservationists. Here we focus on the implementation of well-being monitoring, specifically on the implications of having multiple stakeholders involved. We focus on interventions in poor rural areas that often have weak systems of governance, and consider specifically the well-being of local beneficiaries or participants in such interventions. Larger scale concepts such as national well-being (as used by the UK Government; ONS, 2011; and the Government of Bhutan; CBS, 2012) are beyond the scope of this paper.

Firstly we briefly review the multifaceted concept of wellbeing that is being used differently across different fields, from subjective happiness at the national scale (ONS, 2011) to individual empowerment within farming communities (Friis-Hansen \& Duveskog, 2012). We then consider who wants to measure well-being and why, a question that directly influences the conception of well-being and perceptions of success in environmental interventions. It is necessary to develop a greater understanding of the positions, interests and subtle agendas of stakeholders when considering how success is defined for environmental interventions, particularly when that success is measured in human rather than biophysical terms. We do not address how to measure well-being because several methodological reviews already exist (e.g. Schreckenberg et al., 2010; Angelsen et al., 2011; Richards \& Panfil, 2011). Furthermore, we do not claim to identify the best approach to using the concept of wellbeing but instead consider the trade-offs and dilemmas that policy makers and practitioners face when applying the concept within the context of environmental interventions. Two of these trade-offs relate to the concept of wellbeing, and two to its operationalization. By making these trade-offs explicit, and highlighting the power dynamics that may lie behind particular approaches to monitoring well-being, we aim to promote more informed decisionmaking about how best to operationalize the concept of well-being in conservation.

\section{What is well-being?}

There are numerous definitions of well-being, each of them using a slightly different emphasis, albeit often with significant overlap (see Agarwala et al., 2014 for a review). In this section we briefly outline objective and subjective approaches to well-being, before moving on to discuss hybrid approaches. We use this review as a foundation for exploring our first two trade-offs: single- vs multi-dimensional operationalizations of well-being, and the emphasis on the positive rather than negative aspects of life.

\section{Objective approaches}

'Poverty is pronounced deprivation in well-being' (World Bank definition; Haughton \& Khandker, 2009)

Objective changes in this context refer to observable, material changes in the external world surrounding an individual. In high-level, macro-scale development literature, such as the UN Millennium Development Goals and the World Bank resource documents, poverty and well-being are seen as objective concepts that are mutually exclusive, as in the above definition. This broad approach results in a concept that can include a number of different factors such as basic materials for a good standard of living, health, nutrition, security, social relations and freedom of choice. Objective approaches characterize many other policy areas; for example, the health discourse suggests that wellbeing is determined by good physical health, which can be further improved by engaging in positive behaviours (as exemplified by the mixed content of the UK Government's web page on health and well-being; Government of the UK, 2012). Economists widely use well-being interchangeably with 'gain' so that the concept is synonymous with a person's objective access to rights, goods and services (Baldock, 2007). Given that well-being by definition is an internal not external state, the objective approach is not so much looking at well-being itself as at the factors that influence well-being. Even when using objective proxies it is far from straightforward to identify correctly the defining factors. Focusing on objectivity we face a conundrum: how, using a purely objective approach, can the genuine sense of well-being commonly described as being felt in extremely poor communities be explained? 


\section{Subjective approaches}

'Well-being refers to the emotional quality of an individual's everyday experience-the frequency and intensity of experiences of joy, stress, sadness, anger and affection that makes one's life pleasant or unpleasant' (Kahneman \& Deaton, 2010)

Focusing on an individual's experience, subjective definitions such as this capture how a multitude of external, objective factors are translated into internal experiences of well-being. In psychology, where subjective approaches have been adopted most strongly, the eudaimonic approach proposes that happiness is sourced in the experience of life satisfaction and fulfilment, while the hedonic approach engages with the more familiar concept that happiness is sourced in the experience of pleasure and pain (as reviewed by Ryan \& Deci, 2001). Both approaches place considerable emphasis on individual personality but do not always correlate because the expectations of people within the same cohort, and of individuals through their lives, can differ significantly. For example, different expectations can cause people with the same emotional well-being and resources to experience very different life satisfaction (Kahneman \& Kruger, 2006). Both approaches refer to the term happiness, which is increasingly fashionable with national governments; e.g. the Government of Bhutan's pioneering concept of Gross National Happiness (CBS, 2012) and the UK Government's commissioning of a national well-being study that uses happiness as the cornerstone of its work (ONS, 2011). However, although subjective approaches draw upon relatively direct indicators of individuallyexperienced well-being, Keyes \& Waterman (2003) assert that they don't tell enough of the story and so use a slightly hybridized definition that includes internal states as well as external objective capabilities: '[well-being] encompasses positive functioning states that include successful accomplishing of social challenges and tasks'.

\section{Hybrid approaches}

'Well-being is a state of being with others, where human needs are met, where one can act meaningfully to pursue one's goals, and where one enjoys a satisfactory quality of life' (Gough \& McGregor, 2007)

The Wellbeing in Developing Countries research group, a substantial contributor to the well-being literature since 2002, utilizes the above definition, explaining that the blend of the objective and subjective concepts transcends both by recognizing the way each is socially constructed (Gough \& McGregor, 2007). Sen (1999) pioneered this mixed approach by emphasizing that people are likely to subjectively experience their objective deprivation very differently. The hybrid approach has emerged from the social sciences and gained traction in other fields such as health (e.g. the Gallup-Healthways definition: 'well-being is a state of complete physical, mental and social health'; Gallup, 2009), economics (e.g. the new economics foundation definition: 'well-being is functioning well, having positive feelings day-to-day and overall, and thinking your life is going well'; NEF, 2012), and government policy (e.g. the Australian Bureau of Statistics definition: 'wellbeing is a health or sufficiency in all aspects of life'; ABS, 2001). Although using a hybridized definition promotes a holistic approach to monitoring the impacts of interventions on people and ecosystems, there is a danger that being broadly inclusive can render the well-being concept overly complex and difficult to operationalize. As a result, policy makers and practitioners typically face trade-offs when conceptualizing and measuring the effects of interventions on well-being.

\section{Trade off 1: single vs multi-dimensional definitions}

Some definitions of well-being are more complicated than others and this has implications when planning and monitoring environmental interventions while explicitly considering their impact upon human well-being. If a (relatively) one-dimensional definition is used, such as 'well-being is determined by an individual's experience of life satisfaction and fulfilment' (the eudaimonic approach; Kahneman \& Deaton, 2010), then well-being is readily conceptualized and therefore more easily utilized in monitoring, fulfilling the needs of interventions with very specific interests. The major drawback of such an approach to well-being is that it is narrow: it may at best only partially describe the changes that human subjects experience, in so doing defeating the point of using well-being as a nuanced and holistic approach. Conversely, a multi-dimensional definition such as 'well-being is determined by all aspects that are important to an individual' (the Australian Bureau of Statistics approach) is so widely descriptive that any operationalization of the concept is likely to require the inclusion of many subtle elements that contribute to well-being in order to capture the genuine social impacts of an intervention. However, this array of elements may make understanding, monitoring and therefore robust measurement of well-being change an impractically large and complex undertaking. To reconcile this trade-off, policy makers and practitioners may choose to select a manageable set of elements from a pre-defined pool of appropriate indicators, in line with the approach outlined by Bossel (2001).

\section{Trade off 2: emphasizing positive well-being vs a focus on negative well-being}

In general, the use of the term well-being rather than the term poverty represents a conceptual shift towards a more positive approach to development, focusing on what is good and improves people's lives rather than primarily what is bad or lacking (NEF, 2012). However, there is the potential that this focus on desirable states 
could neglect to address the negative aspects of people's lives. Well-being is reduced by 'harms' such as poverty, malnourishment, social exclusion and more extremely, war, and governments should take steps to reduce these harms (McGregor, 2011). In a conceptual parallel to the differentiation between satisfiers, pseudo-satisfiers and pathogens in Max-Neef's (1991) discourse on human needs, well-being needs to be considered both in relation to the active presence or absence of positive components, and in relation to the presence or absence of harms. Particularly in areas where there is substantial poverty, conflict and land seizure, where environmental interventions can occur, the changing presence of harms may be more relevant to the overall balance of someone's life. For example, an individual may have improving family relationships and increased access to health and education services, but their well-being may remain overwhelmingly affected by social issues such as alcoholism in the community, or ecosystem dis-services such as flooding or drought. Objective approaches should equally cover positive and negative aspects of a person's surrounding environment while subjective information may reveal how these negative and positive factors are internally processed, summed and expressed. Subjective information can also serve to test the relevance of the objective measures: if the objective overview shows a person to be surrounded by more positive well-being factors than negative factors, but they convey poor subjective well-being, the monitoring process may well be missing key elements that shape well-being for that particular person, community or society.

\section{Who wants to monitor well-being and why?}

Well-being can be conceptualized by external personnel and used comparatively in different locations and over time, or conceptualized by local people themselves and be as relevant as possible to those affected by an intervention at a particular point in time (e.g. Ferraro \& Pattanayak, 2006). One key factor that frequently determines the approach taken to well-being in environmental interventions is who is involved in the project and why they are interested in monitoring well-being. Mapping the range of stakeholders involved in environmental interventions is a typical step in planning a monitoring programme. However, practitioners rarely explore the possible underlying agendas of each stakeholder (for examples, see Malan, 2008; MacDonald, 2010), as these more subtle agendas are not easily evidenced and often are only understood after a considerable time working in a locality. In Table 1, we describe a hypothetical round-table discussion for planning and implementing an intervention, incorporating a limited selection of caricatured perspectives that stakeholders may have on why it is important to monitor well-being.
Differences in perspectives stem from disparate motivations for involvement in interventions. Table 1 breaks down some typical perspectives, showing the public narrative openly expressed by stakeholders as well as potential underlying strategic interests. These perspectives are generalized from our own experiences and are by no means exhaustive; the aim is to raise common issues relating to well-being. From them, we draw out two key trade-offs relating to operationalizing well-being.

\section{Trade-off 3: internal vs external validity}

With contrasting interests in monitoring well-being (Table 1), subtle power struggles may occur as different stakeholders attempt to have their own needs met. One particularly important outcome of this power struggle is the extent to which monitoring of well-being is focused on external or internal validity. Internal and external validity in this context refers to whom a framework, project or system is primarily serving with respect to investigation and information provision. A well-being monitoring system that is internally valid is well tailored to a specific area or population and represents the local expressions and determinants of well-being. It wouldn't necessarily be as transferable or applicable to other areas or populations, or even to the same population over time, as an externally valid system would be. Both types of validity are important. Internal validity or relevance will often determine the local social sustainability of an intervention, whereas external validity or relevance ensures that, by focusing on spatial or temporal project comparisons, interventions may lead to more wide-reaching benefits and thus potentially better returns on environmental investments. In practice, external validity frequently dominates because of the greater political and economic power of high-level external organizations (for example, see Scheske, 2012). Schmidt \& Bullinger (2007) describe this trade-off in validity and propose an adaptable cross-cultural approach that includes both external and internal validity.

\section{Trade-off 4: quantitative vs qualitative understanding}

Quantitative approaches frequently underpin externally valid interventions and generate numerical data that can be analysed using statistical methods and presented concisely. On the other hand qualitative approaches often provide greater detail about the meaning and experience of well-being and are regularly used in internally valid interventions where issues of local importance are explored within complex social systems (Krauss, 2005; Dominguez Gomez et al., 2010). Qualitative information may be preferred by local communities as well as academic social scientists. The two types of understanding are largely 
TABLE 1 A stylized representation of the perspectives of typical stakeholders in environmental interventions and the effect of these perspectives on well-being monitoring.

\begin{tabular}{ll}
\hline Stakeholder group & Public narrative \\
\hline $\begin{array}{l}\text { Community leaders } \\
\text { ('Will it help our }\end{array}$ & $\begin{array}{l}\text { Community leaders in rural areas have responsibilities } \\
\text { to their communities to manage natural \& human re- }\end{array}$ \\
& $\begin{array}{l}\text { sources. Their interest in examining the impact an } \\
\text { intervention has on their people (monitoring well- } \\
\text { being) comes from a desire to assess whether it is so- } \\
\text { cially sustainable through directly improving the lives of } \\
\text { the community, helping them towards their own de- } \\
\text { velopment goals. }\end{array}$
\end{tabular}

Grass-roots NGOs ('Are we doing a good job?')

National governments ('Are we allocating resources appropriately?')

International NGOs \& multi-lateral agencies ('Is our support helping \& can it be replicated?')
Usually staffed by a mixture of non-resident experts \& local people, these NGOs often take on the responsibility for solving environmental problems through managing projects. They prefer to be seen as doing this effectively \& with sensitivity to the interests \& concerns of local people.

Governments have the same responsibilities as community leaders but at a much larger scale. Addressing environmental problems through interventions will always require some government involvement through staffing or permissions. When monitoring well-being, governments may wish to gather international-standard statistics for their records, assemble information that shows concern for local people \& the decentralization of power, \& undertake an assessment of the effectiveness of their policies for improving the lives of the population (e.g. Jordan et al., 2010; Biddle, 2011; ONS, 2011). The standardization of information will often come at the expense of meaningful local details, a concept defined as 'legibility' by Scott (1998).

At this level NGOs \& agencies become major influences on national \& international policy while still facilitating ground-level activity through project work. Their pri-

mary concern in monitoring well-being is to assess the impact of environmental interventions \& the effectiveness of related policies (e.g. Cooke et al., 2007; Gjoksi, 2010), both of which they may be supporting through finance or personnel. In doing this the organization shows that they have significant technical expertise in the particular policy area. Furthermore, as environmental NGOs have traditionally had nature at the top of their priorities, incorporating well-being monitoring shows funding bodies, colleagues \& participants that they are integrating the heart of the development agenda (i.e. alleviating poverty) into their work (Roe, 2008).

\section{Strategic interests}

Individuals \& leaders have to deal with the expectation of development \& that living standards will continue to improve, which is a pressure that grows more acute with increasing global connectivity. Well-being data will help them answer questions about this, \& so show their communities that they've been leading well. This type of information could also be used to manipulate community opinion to consolidate power \& maintain elite status. Community leaders are also aware that they have to be compliant \& capable in order to earn trust \& funds from projects, \& may therefore take an interest in monitoring whatever indicators the project implementers suggest are required.

To attract continued financial support project managers are obliged to provide objective data to their funding body on the impact that an environmental intervention has on the beneficiaries of the project (e.g. Friis-Hansen \& Duveskog, 2012). These data need to show that their actions are actually leading to improvements, thus implying causality. Also these NGOs may be used as vehicles for other agendas by the local employees (e.g. pushing political messages during project meetings in the communities) \& well-being data can be used as leverage for this.

Governments may have an interest in indicating that environmental problems are generally a result of poor local resource management \& not national mismanagement. This may include superficially devolving as much responsibility as possible to communities while operationally retaining as much power as possible (Ribot et al., 2006). Specific information about the well-being of local communities may allow government departments \& ministers to manage this local-national power dynamic in their own favour. They may also be keen to leverage international donor funding through the demonstration of both current need \& effective governance \& reporting.

If the intervention \& its well-being monitoring framework are functional, the NGO/agency may wish to export the model to other regions or nations in similar situations. Because well-being is currently very topical in conservation \& development, the organization may seek to be a pioneer in developing a well-being toolkit, showing leadership in good practice, raising their international profile, \& attracting more funding. 
Table 1 (Cont.)

\begin{tabular}{|c|c|c|}
\hline Stakeholder group & Public narrative & Strategic interests \\
\hline $\begin{array}{l}\text { Businesses ('What } \\
\text { are the needs of the } \\
\text { market?') }\end{array}$ & $\begin{array}{l}\text { The term 'business' is used here to describe for-profit } \\
\text { organizations whose existence depends on financial } \\
\text { solvency. The traditional public narrative for businesses } \\
\text { suggests 'what is good for us is good for you; help grow } \\
\text { our business by buying from us so we can provide for } \\
\text { more of your needs.' By monitoring well-being, busi- } \\
\text { nesses know more about what people want \& can } \\
\text { thereby serve local consumers better, as well as dem- } \\
\text { onstrate corporate social responsibility. }\end{array}$ & $\begin{array}{l}\text { Well-being data may help a business to understand } \\
\text { better local people as consumers, co-producers or clients } \\
\text { (e.g. Rangan et al., 2011), \& through this understanding } \\
\text { the business is primarily looking for opportunities to } \\
\text { grow profits \& bring returns for shareholders. Ethical } \\
\text { practices that address the well-being of local people are } \\
\text { often a secondary concern, either based on legislative } \\
\text { obligations or making the products more marketable to } \\
\text { ethical consumers elsewhere. }\end{array}$ \\
\hline $\begin{array}{l}\text { Academia ('Is well- } \\
\text { being a good con- } \\
\text { cept to use?') }\end{array}$ & $\begin{array}{l}\text { Academics aim to further knowledge. They may be in- } \\
\text { terested in monitoring well-being for all the above rea- } \\
\text { sons, depending on the discipline, but are attracted to } \\
\text { nascent fields \& open research questions, aiming to offer } \\
\text { balanced, expert views \& innovative insights. The use of } \\
\text { local well-being as a concept is underdeveloped in the } \\
\text { literature \& so the operational challenges of monitoring } \\
\text { well-being may be considered a primary research focus } \\
\text { (e.g. Coulthard et al., 2011; Khumalo et al., 2012). }\end{array}$ & $\begin{array}{l}\text { Academics develop a career by exhibiting expertise \& } \\
\text { innovative analysis which then attracts funding. Because } \\
\text { emerging or exciting fields also attract funding \& can be } \\
\text { published in high-impact journals, there may be a ten- } \\
\text { dency to re-brand ongoing research to also encompass } \\
\text { well-being (De Rond \& Miller, 2005). Furthermore, as } \\
\text { well-being is a growing policy concern, \& as the real- } \\
\text { world impact of academic research is increasingly being } \\
\text { measured by research funders, academics may gravitate } \\
\text { towards it. }\end{array}$ \\
\hline
\end{tabular}

complementary because they provide different methods with which to investigate and represent multifaceted wellbeing (Healy \& Perry, 200o). However, quantitative data are often viewed as sufficiently robust for policy formulation, whereas qualitative information may be considered extraneous or preliminary instead of providing essential context (Pullin et al., 2004). This disparity frequently arises from a misconception of what constitutes objective data (numerical data are often perceived as objective; Choi et al., 2005), as well as variation in concepts and terminology, which can lead to misunderstandings about the value of different types of knowledge (Fox et al., 2006; Drury et al., 2011) and a reduction in the quality or effectiveness of well-being assessments.

\section{Discussion}

'[there is a] more widely accepted view, associated with Sen (1999), which is that human well-being depends on a range of functions and capabilities that enable people to lead a good life, each of which needs to be directly and objectively measured and which cannot, in general, be aggregated into a single summary measure' (Deaton, 2008)

Well-being is a holistic concept that can be used to promote a more comprehensive understanding of the human part of an ecosystem. Natural scientists and development workers involved in environmental interventions have traditionally tended towards concise, quantitative results to evaluate the impact of their projects and demonstrate success to donors and colleagues. It therefore follows that these practitioners will, for the most part, look for similar externally-orientated outputs when considering well-being. However, significant local input is required to provide a nuanced understanding of the local situation within which an intervention takes place, a necessary requirement if the intervention is aiming to improve (or not harm) the human condition (Scott, 1998).

The power struggle to gain control or influence over an intervention is centrally important because those who dominate will determine which conceptualization and approach to well-being is used and therefore what is monitored during the ongoing project. In conservation, local voices are often overpowered by more influential bodies such as local elites, investors and the government (Brockington, 2003; Scheske, 2012). To achieve greater equity and intervention sustainability, policy makers and practitioners should endeavour to give local people influence over project design as well as facilitating the genuine airing of local perspectives at all levels (e.g. in national and international-level project meetings and not just community-level meetings).

Using the well-being concept in developing a monitoring programme for the social impacts of an intervention may improve understanding of local context while raising the profile of local contributions to the planning process. Navigating this process is only possible when the subtle as well as the obvious motivations and agendas of the various stakeholders are explicitly understood. Promoting internal validity may lead to the further integration of qualitative approaches and human narratives with the classically dominant quantitative methods, shaping the more holistic methodology advocated by Thomas (2008). However, there are two generally important cautions here: (1) the project team will consequently need to be bigger, more inter-disciplinary and may need longer to decide upon a monitoring plan, as a result of the different disciplinary thinking, language and traditions (Pooley et al., 
2014); and (2) careful consideration should be given to whether enhancing participation of local people is both appropriate and beneficial; assuming more participation is good is a value-statement and is not universally applicable (Bishop \& Davis, 2002).

A dilemma emerges as well-being measurement shifts towards more internal validity and a stronger focus on subjective well-being, as we advocate. The concept of well-being is itself constructed by individuals in a relational context (McGregor, 2008). As such the entire conceptual framework for an individual can change radically as the relational situation changes. As a complex concept with a potentially shifting baseline, measuring well-being over time to determine the success of an intervention becomes extremely challenging. For example, Batwa Pygmies in East and Central Africa were displaced from their forest homes as a result of gazetting national parks (Lewis \& Richmond, 2000). Their well-being was previously centred on traditional craft and hunter-gathering strategies but is now increasingly influenced by access to education and justice as they seek to flourish while living in close contact with surrounding societies (Lewis \& Richmond, 2000). Constructing an a priori framework to track changes in the components of wellbeing through these changing circumstances would be extremely difficult.

To negotiate the trade-offs we have identified there is firstly a requirement to understand the needs and perspectives of each stakeholder and determine the degree of external and internal validity that is needed from the monitoring (Table 1, trade-off 3). Subsequently, agreement can be reached on a definition and conceptual framework for well-being that includes a range of subjective and objective dimensions (trade-off 1 ) and the balance of positive and negative factors to be monitored (trade-off 2). Finally, the quantitative and qualitative contributions can be decided when developing actual measures (trade-off 4 ).

The issues examined here lead to three main conclusions. Firstly, individual well-being is not a simple concept that can be easily defined and measured to see how an intervention is affecting people. It is multifaceted and contains a mixture of positive and negative elements, which are likely to be affected by environmental interventions in complex, often indirect ways. Secondly, policy makers and practitioners should be aware of the need to give local perspectives on well-being more attention when designing and implementing environmental interventions. In doing this the local relevance of indicators may be improved, stakeholder equity may be enhanced, and more revealing methodologies may shape monitoring systems. Thirdly, this is only possible when the underlying motivations of each of the stakeholder groups are explicitly understood. Finding a fair, feasible and fitting balance of trade-offs in monitoring well-being will help shape more successful environmental interventions in the future.

\section{Acknowledgements}

We acknowledge the support of the Natural Environment Research Council's Valuing Nature Network (VNN) project and the ESRC/DFID project Measuring complex outcomes of environment and development interventions. BPF would like to acknowledge the support of the Economic and Social Research Council. We thank all the members of the VNN project team and the attendees at the VNN well-being project workshops for their inputs and insights to this work.

\section{References}

Agarwala, M., Atrinson, G., Palmer Fry, B., Homewood, K., Mourato, S., Rowcliffe, J.M. et al. (2014) Assessing the relationship between human well-being and ecosystem services: a review of frameworks. Conservation and Society, 12, 437-449.

Angelsen, A., Larsen, H.O., Lund, J.F., Smith-Hall, C. \& Wunder, S. (eds) (2011) Measuring Livelihoods and Environmental Independence: Methods for Research and Fieldwork. Earthscan, Edinburgh, UK.

ABS (Australian Bureau of Statistics) (2001) Australian Bureau of Statistics: Measuring Well-being. Http:/www.abs.gov.au/ AUSSTATS/ ABS@.NSF/o/B176042438EE2331CA2571B70ooA43A7? opendocument [accessed 2 September 2015].

BAHUGUnA, V. (2000) Forests in the economy of the rural poor: an estimate of dependency. Ambio, 29, 126-129.

BALDOCK, J. (2007) Social policy, social welfare, and the welfare state. In Social Policy, 3rd edition (eds J. Baldock, N. Manning \& S. Vickerstaff), pp. 7-26. Oxford University Press, Oxford, UK. Biddle, N. (2011) Definitions of Well-being and their Applicability to Indigenous Policy in Australia. 2011 CAEPR lecture series: Measures of indigenous well-being and their determinants across the lifecourse. Centre for Aboriginal Economic Policy Research, Australian National University, Canberra, Australia.

Bishop, P. \& DAvis, G. (2002) Mapping public participation in policy choices. Australian Journal of Public Administration, 61, 14-29.

Blomley, T. \& Franks, P. (2009) Making Participatory Forest Management Work for the Poor. CARE Denmark, Copenhagen, Denmark.

Bossel, H. (2001) Assessing viability and sustainability: a systemsbased approach for deriving comprehensive indicator sets. Ecology and Society, 5(2), 12.

Brashares, J.S. \& SAM, M.K. (2005) How much is enough? Estimating the minimum sampling required for effective monitoring of African reserves. Biodiversity and Conservation, 14, 2709-2722.

Brockington, D. (2003) Injustice and conservation: is local support necessary for sustainable protected areas? Policy Matters, 12, 22-30.

CBS (Centre for Bhutan Studies) (2012) Gross National Happiness. Http://www.grossnationalhappiness.com/ [accessed 2 September 2015].

Choi, B., Pang, T., Lin, V., Puska, P., Sherman, G. \& Goddard, M. (2005) Can scientists and policy makers work together? Journal of Epidemiology and Community Health, 59, 632-637.

Christie, P. (2004) Marine Protected Areas as biological successes and social failures in Southeast Asia. American Fisheries Society Symposium, 42, 155-164.

Cooke, M., Mitrou, F., Lawrence, D., Guimond, E. \& Beavon, D. (2007) Indigenous well-being in four countries: an application of the 
UNDP's Human Development Index to indigenous peoples in Australia, Canada, New Zealand and the United States. BMC International Health and Human Rights, 7(9).

Coulthard, S., Johnson, D. \& McGregor, J.A. (2011) Poverty, sustainability and human well-being: a social well-being approach to the global fisheries crisis. Global Environmental Change, 21, 453-463.

Danielsen, F., Skutsch, M.M., Burgess, N.D., Jensen, P.M., Andrianandrasana, H., KARKY, B.S. et al. (2011) At the heart of REDD+: a role for local people in monitoring forests? Conservation Letters, 4, 158-167.

De Rond, M. \& Miller, A. (2005) Publish or perish: bane or boon of academic life? Journal of Management Inquiry, 14, 321-329.

Dominguez Gomez, J., Roig Merino, B. \& Aledo Tur, A. (2010) The identity of sociology or what to do when the universe is unknown: qualitative solutions against quantitative obsession. Spatial and Organizational Dynamics, 5.

Drury, R., Homewood, K. \& Randall, S. (2011) Less is more: the potential of qualitative approaches in conservation research. Animal Conservation, 14, 18-24.

Ferraro, P.J. \& Pattanayak, S.K. (2006) Money for nothing? A call for empirical evaluation of biodiversity conservation investments. PLoS Biology, 4, 482-488.

Fox, H., Christian, C., Nordby, C., Pergam, O., Peterson, G. \& PYкE, C. (2006) Perceived barriers to integrating social science and conservation. Conservation Biology, 20, 1817-1820.

Friss-Hansen, E. \& Duveskog, D. (2012) The empowerment route to well-being: an analysis of Farmer Field Schools in East Africa. World Development, 40, 414-427.

Gallup (2009) Gallup-Healthways Well-being Index: Methodology Report for Indexes. Http://wbi.meyouhealth.com/files/GallupHealth waysWBI-Methodology.pdf [accessed 2 September 2015].

Gjoksi, N. (2010) International Approaches to Measure Wealth and Well-being in the Context of Sustainable Development. ESDN Case Study No. 3. European Sustainable Development Network. Http:// www.sd-network.eu/pdf/case\%2ostudies/o3_ESDN\%20Case\%20Study \%203_FINAL.pdf [accessed 2 September 2015].

Gough, I. \& McGregor, J.A. (2007) Well-being in Developing Countries: From Theory to Research. Cambridge University Press, Cambridge, UK.

Government of the UK (2012) Health and Well-being. Http://www. gov.uk/government/publications/health-and-wellbeing-introductionto-the-directorate/health-and-wellbeing-introduction-to-the-directorate [accessed 2 September 2015].

HARVEY, P. \& REED, R. (2007) Community-managed water supplies in Africa: sustainable or dispensable? Community Development Journal, 42, 365-378.

Haughton, J. \& Khandker, S.R. (2009) Handbook on Poverty and Inequality. World Bank, Washington, DC, USA.

Healy, M. \& Perry, C. (2000) Comprehensive criteria to judge validity and reliability of qualitative research within the realism paradigm. Qualitative Market Research: An International Journal, 3 $118-126$.

Jordan, S.J., Hayes, S.E., Yoskowitz, D., Smith, L.M., Summers, J.K., Russel, M. \& Benson, W.H. (2010) Accounting for natural resources and environmental sustainability: linking ecosystem services to human well-being. Environmental Science and Technology, 44, 1530-1536.

Kahneman, D. \& Deaton, A. (2010) High income improves evaluation of life but not emotional well-being. Proceedings of the National Academy of Sciences of the United States of America, 107, 16489-16493.

Kahneman, D. \& Kruger, A.B. (2006) Developments in the measurement of subjective well-being. Journal of Economic Perspectives, 20, 3-24.
Kareiva, P. \& Marvier, M. (2012) What is conservation science? BioScience, 62, 962-969.

Kepe, T., Saruchera, M. \& Whande, W. (2004) Poverty alleviation and biodiversity conservation: a South African perspective. Oryx, 38, 143-145.

Keyes, C. \& Waterman, M. (2003) Dimensions of well-being and mental health in adulthood. In Well-being: Positive Development Across the Life Course (eds N. Bornstein, L. Davidson, C. Keyes \& K. Moore), pp. 477-497. Psychology Press, New Jersey, USA.

Khumalo, I.P., Temane, Q.M. \& Wissing, M.P. (2012) Sociodemographic variables, general psychological well-being and the mental health continuum in an African context. Social Indicators Research, 105, 419-442.

KRAUSS, S. (2005) Research paradigms and meaning making: a primer. The Qualitative Report, 10, 758-770.

Lenzen, M., Moran, D., Kanemoto, K., Foran, B., Lobefaro, L. \& Geschкo, A. (2012) International trade drives biodiversity threats in developing nations. Nature, 486, 109-112.

Lewis, J. \& Richmond, S. (eds) (2000) The Batwa Pygmies of the Great Lakes Region. Minority Rights Group International, London, UK.

Liu, J., Dietz, T., Carpenter, S., Alberti, M., Folke, C., Moran, E. et al. (2007) Complexity of coupled human and natural systems. Science, 317, 1513-1516.

MacDonald, K.I. (2010) Business, biology, and new 'fields' of conservation: The World Conservation Congress and the renegotiation of organizational order. Conservation and Society, 8, 256-275.

Malan, L.C. (2008) Beyond the debate: exploring the underlying values and assumptions of biodiversity conservation in protected areas. $\mathrm{PhD}$ thesis. Antioch University, New England, USA.

MaX-Neef, M. (1991) Human Scale Development: Conception, Application and Further Reflections. The Apex Press, New York, USA.

McGregor, A. (2011) The promotion of global well-being can drive the development agenda. Http://www.guardian.co.uk/globaldevelopment/poverty-matters/2011/aug/o8/global-wellbeing-drivedevelopment-agenda [accessed 16 February 2012].

McGregor, J.A. (2008) Well-being, Poverty and Conflict. Report number: 1/o8. WeD Group, Bath, UK.

Millennium Ecosystem Assessment (2005) Ecosystems and Human Well-being: Synthesis. Island Press, Washington, DC, USA.

Milner-Gulland, E.J., McGregor, J.A., Agarwala, M., Atrinson, G., Bevan, P., Clements, T. et al. (2014) Accounting for the impact of conservation on human well-being. Conservation Biology, 28, 1160-1166.

NEF (New Economics Foundation) (2012) Measuring Well-being: A Guide for Practitioners. New Economics Foundation, London, UK.

ONS (Office for National Statistics) (2011) Measuring what Matters. National Statistician's Reflections on the National Debate on Measuring National Well-being. Office for National Statistics, Newport, UK. Http://www.ons.gov.uk/ons/guide-method/ user-guidance/well-being/publications/measuring-what-mattersnational-statistician-s-reflections-on-the-national-debate-on-measuringnational-well-being.pdf [accessed 2 September 2015].

Pooley, S., Mendelsohn, A. \& Milner-Gulland, E.J. (2014) Hunting down the chimera of multiple disciplinarity in conservation science. Conservation Biology, 28, 22-32.

Pullin, A.S., Knight, T.M., Stone, D.A. \& Charman, K. (2004) Do conservation managers use scientific evidence to support their decision-making? Biological Conservation, 119, 245-252.

Rangan, V.K., Chu, M. \& Petкoski, D. (2011) Segmenting the base of the pyramid. Harvard Business Review. June 2011. Http://hbr.org/ 2011/o6/the-globe-segmenting-the-base-of-the-pyramid [accessed 2 September 2015]. 
Ribot, J., Agrawal, A. \& Larson, A. (2006) Recentralizing while decentralizing: how national governments re-appropriate forest resources. World Development, 34, 1864-1886.

Richards, M. \& Panfil, S.N. (2011) Social and Biodiversity Impact Assessment (SBIA) Manual for REDD+ Projects: Part 1 - Core Guidance for Project Proponents. Climate, Community \& Biodiversity Alliance, Forest Trends, Fauna \& Flora International, and Rainforest Alliance, Washington, DC, USA.

RoE, D. (2008) The origins and evolution of the conservation-poverty debate: a review of key literature, events and policy processes. Oryx, 42, 491-503.

RyAn, R. \& DECI, E. (2001) On happiness and human potential: a review of research on hedonic and eudaimonic well-being. Annual Review of Psychology, 52, 141-166.

SCHESKE, C. (2012) A critical analysis of socio-economic monitoring in the context of community-based marine conservation. MSc thesis. Imperial College London, London, UK. Http://www.iccs.org.uk/wpcontent/thesis/consci/2012/Scheske.pdf [accessed 2 September 2015].

Schmidt, S. \& Bullinger, M. (2007) Cross-cultural quality of life assessment approaches and experiences from the health care field. In Well-being in Developing Countries: from Theory to Research (eds I. Gough \& A. McGregor), pp. 219-241. Cambridge University Press, Cambridge, UK.

Schreckenberg, K., Camargo, I., Withnall, K., Corrigan, C., Franks, P., Roe, D. et al. (2010) Social Assessment of Conservation Initiatives: A Review of Rapid Methodologies. Natural Resource Issues No. 22, IIED, London, UK.

Scotт, J. (1998) Seeing Like a State: How Certain Schemes to Improve the Human Condition have Failed. Yale University Press, New Haven, USA.
Sen, A. (1999) Development as Freedom. Oxford University Press, Oxford, UK.

Skutsch, M.M., Van Laake, P.E., Zahabu, E., Karky, B.S. \& Phartiyal, P. (2009) Community monitoring in REDD+. In Realizing REDD+: National Strategy and Policy Options (ed. A. Angelsen), pp. 101-112. CIFOR, Bogor, Indonesia.

Sommerville, M., Jones, J.P.G., Rahajaharison, M. \& MilnerGulland, E.J. (2010) The role of fairness and benefit distribution in community-based payment for environmental service interventions: a case study from Menabe, Madagascar. Ecological Economics, 69, 1262-1271.

Tномаs, B.K. (2008) Methodological debate in poverty studies: towards 'participatory qual-quant'? Development in Practice, 18, 280-288.

Waylen, K., Fischer, A., McGowan, P., Thirgood, S. \& MilnerGulland, E.J. (2010) The effect of cultural context on the success of community-based conservation interventions. Conservation Biology, 24, 1119-1129.

\section{Biographical sketches}

Ben Palmer Fry has advised on the design of a community-based REDD+ MRV protocol. His experience of community engagement comes mostly from East Africa, through Kulika Uganda and Tearfund Southern Sudan, and of forest monitoring through work in Argentina. This paper is the result of an interdisciplinary collaboration of a team of natural scientists, economists, and anthropologists, brought together to study this topic through the NERC Valuing Nature Network (http://www.iccs.org.uk/well-being). 